\title{
Understanding Proximate Factors Associated With Perpetration of Intimate Partner Violence by Men In India
}

Bigi Thomas, ${ }^{+*}$ H.P Trivedi, ${ }^{\dagger}$ Rema Subhash, ${ }^{\dagger}$ and Sangita N. Pathak ${ }^{\dagger}$

\section{Abstract}

At a time when there is a severe dearth of men centric versions of intimate partner violence and the perpetuation of the same by men shows anomalous surge around the world, it is essential to investigate the predictive factors of the same with its intricacies from perpetrators perspectives too. Understanding the factors instrumental in making perpetrators of violence, especially when violence on women is the demonstration of men's failure to appreciate the inherent poise and parity of women, can enable us to have policy interventions to involve men as a part of solution in our efforts towards combating all forms of violence, resulted from aggressive masculinity with gender stereotypes, which sanctions use of violence as well as a sense of entitlement over women.

This study attempts to encapsulate the links between IPV perpetration and perpetrators' attitude towards gender equality, childhood gender inequity \& violence experiences and explores the associations between education, age, occupation and income of perpetrators on IPV. A quantitative research design was followed in this study where 1600 men from four different districts, having different gender equality and development indices, within Gujarat, India were selected by proportionate random sampling.

The results of this study vividly demonstrate the ubiquity of IPV, a petrifying crime pervasive around the world. It also underlines how strong and deeply rooted patriarchal attitudes internalised within men are intricately linked to their inclination towards IPV. Childhood gender inequity, as well as violence experiences of men, is also emerged as a set of proximate factors found to be significantly correlated with their propensity to be violent towards women. This study immensely contributes towards policy recommendations which will help generations to disapprove of violence on women and grow up with gender equity attitudes.

Keywords: Intimate Partner Violence; Men; Childhood; Gender Inequity Experience; Childhood Violence Experience; Gujarat; India

\footnotetext{
+ Sardar Patel University, Gujarat, India

${ }^{*}$ Corresponding Author, Reader, Department of Social Work, Sardar Patel University, Gujarat- 388120, Email: bigisrsh@gmail.com
} 


\section{Introduction}

Intimate partner violence perpetrated upon women has been acknowledged across the world, as one of the most devastating forms of gender-based violence. It is considered as a gross human rights violation, which leads to grave as well as enduring physical and mental tribulations for women, their children and, community. Sustainable development of women, families, and societies can be made possible, with comprehensive intervention strategies capable of preventing IPV, which will protect their physical, emotional and financial well-being (Tu \& Lou, 2017, p.1).

Intimate partner violence can be articulated as "any behaviour within an intimate relationship that causes physical, psychological or sexual harm to those in that relationship. It includes acts of physical aggression, psychological abuse, forced sexual intercourse or any other controlling behaviour" (World Health Organization [WHO], 2015, p.1).

In a similar way the Department of Justice, Canada (2016) suggests "it may include a single act of violence or several acts that form a pattern of abuse [and] can have serious and sometimes fatal consequences for victims and for those who see or hear the violence" (p.1).

Numerous health issues, as consequences of different forms of violence by partners, suffered by women include constant pain, impairment, neurological abnormalities, physical and psychological trauma, and infectious diseases (Pines, 2017, p.11). Not only in its very core, violence upon women is an evidence of men's failure to appreciate the innate parity and dignity of women, but also validates their extreme lack of ability, mostly stems from unequal gender hierarchies and power imbalances prevalent in societies, to respect them (United Nations, 2018, p.1).

All over the world, around $30 \%$ of women accounted, at least once in their life, have been subjected to sexual and or physical IPV. At the same time around $38 \%$ of murders of women, reported globally, are done by their male intimate partners (WHO, 2017, p.1). Similarly, a quarter of men from India, who admitted committing sexual violence at some point, perpetrated the same upon a girlfriend or a wife (Priyali, 2015, p.1). Gupta (2014, p.1) also reported that the infliction of IPV on wives was committed by intimate partners than others including strangers.

Indeed IPV victimisation is a universal phenomenon and women constitute the largest share of the victims (Pines, 2017, p.11). A violence-free life is an entitlement of every girl and woman. However, violation of this right within partner relationships is prevalent worldwide in different forms while underprivileged as well as downgraded women are the most assaulted (United Nations, 2017, p.1).

A plethora of research (Alhabib, Nur \& Jones, 2010; Sarkar, 2010 \& Sharma, 2015) has documented the prevalence and predicaments of IPV on women, but very few attempted to conceptualise its risk factors through the lens of the abusers (Yakubovich et al., 2018, p.1). IPV is reported ubiquitous all over India irrespective of class, caste, religion and geographical boundaries. Women are more prone to be victimised by partner violence, especially in traditionally male-dominant cultures, if showed non-adherence to conventionally accepted gender norms. IPV perpetration within intimate relations is found to have an enduring association with the patriarchal ideologies and gender-related cultural attitudes as well as practices of any community (Smith, 2008 \& Thomas, 2018a). Women's' non-endorsement to male dominance as well as their reluctance to respect inequitable gender roles within families have been consistently found to be significantly linked with their violence experiences. Disturbingly in many societies, women also approve this attitude, which subsequently raises the odds of perpetration and victimisation of IPV by their male and female offspring respectively. (Thomas, 2018a, p.607)

This study starts with a literature review that facilitates theoretical understanding about the 
perpetration of IPV by men. Methodology including the scope, coverage as well as samplings of this study is then outlined followed by a discussion on results. Recommendations aiming to help men respect women and condemn violence on them are given at the end.

\section{Intimate Partner Violence: Proximate Factors Related to Perpetrators}

A large body of research has explicitly documented a variety of theoretical perspectives on the aetiology of IPV. Some perpetrator centric studies on intimate partner violence (Saenger, 2000; Marilyn, 2010) have addressed several perpetrators' related proximate factors that make them prone to commit violence against women. These studies argued that men learned to be dominant and aggressive to be in power during socialisation.

While Heise, Pitanguy, and Germaine (1994, p.29) posited that gender socialisation, which glorifies male supremacy and imbues a feeling in men to adhere to patriarchal role norms leads to partner abuse, a large scale study by WHO (2015, p.2) highlighted shreds of evidence for links between IPV and substance abuse.

Significant associations between IPV and child abuse experiences of men have been well documented with profound pieces of evidence in violence studies that spousal abuse is done by those men who in their early years experienced and witnessed violence in their own families. A cross-sectional study by Gil-González, VivesCases, Ruiz, Carrasco-Portiño, and AlvarezDardet (2007, p.14) suggest childhood exposure to violence augments partner violence. At the same time, Johari (2017) proposed that wife abuse is often done by those men reported to be addicts, aggressive, doubtful and financially insecure(as cited in Aziz, Idris, Ishak, Wahid, and Yazid (2018), p. 40).

Similarly a WHO (2017) study also highlighted the associations in the relationship between IPV and perpetrators' inferior levels in education, income and employment status. Internalised patriarchal gender norms, as well as violence experiences, were also found as influencing factors in making men more susceptible to be batterers. Investigations by Aziz et al.(2018) revealed corroborative conclusions that addictions, violent family environments and masculine notions of men are pathways to IPV.

Jewkes (2002) identified strong notions supporting gender stereotypes and male dominance over women as predictive factors of IPV. Dunkle and Jewkes (2017) also postulated that IPV over women is considered as a normal and acceptable way of exerting man's authority over women within families and societies where men assume supremacy and ownership on their wives. Research has long been confirmed that "violence experienced by women is influenced by conditions of gender-based discrimination, often reflected in patterns attributable to" different forms of violence, inextricably embedded in the minds of perpetrators (UNODC, 2018, p.25).

An attempt is made to conceptualise the impact and role of several proximate factors in men's perpetration of IPV by Atkinson, Greenstein, and Lang (2005) and argued that women are more susceptible to be battered at the hands of traditional husbands especially when their masculine identities are threatened due to their failure to earn enough or when their wives earn more than them. This demonstrates how the gender ideologies of husbands are critical, especially when they perceive violence as a way to compensate for their dearth of resources (Gracia \& Merlo, 2016).

Observing the above evidence, it is arguable that men's actions and behaviours are overwhelmingly fashioned by rigid cultural as well as social expectations associated with masculinity and related power imbalances (Hendra, FitzGerald, \& Seymour, 2013). Also, prevailing constructions of masculinity often prescribe that the man is the provider and protector of the family. The inherent pressure this notion can place on men may lead them to show aggressive behaviour, possibly to direct the focus away from their perceived sense of failure in not being able to meet the expectations of this role (Glinski, Schwenke, O'Brien-Milne, \& Farley, 2018). In the light of this background, this research aims to explore the 
proximate factors associated with perpetration of IPV by men in the state of Gujarat. The next session discusses the methodological issues.

\section{Methodology}

The present study illustrates proximate factors attributed to the violent behaviour of men against female partners.

Compared to many other states, the prevalence of physical as well as sexual violence within a marital relationship is high in Gujarat (Gupta, 2014). For the selection of the respondents according to the urban-rural ratio of four districts of Gujarat, a multi-stage proportionate random sampling method was used. Data were drawn from 1600 men (959 urban and 641 rural) aged between 18- 50 and the study comprised 12 towns and 36 villages from four districts of Gujarat, India.

In addition to a detailed interview schedule, covering all demographical, socio-economic details of the respondents, to understand the details of the vital proximate factors of IPV, three standardised tools namely Violence Scale (Thomas, 2018b), Gender Equality Scale (Thomas, 2018c) and an Intimate Partner Violence Scale by Straus (1979) \& Margolin, Burman, John, \& Brien (1990) were administered

Trained male investigators, after having one week thorough orientation about the scope, rationale and sensitive nature of the topic, collected data from 1st February to 31st May 2017. They were trained to understand the importance of creating an environment that facilitates the collection of reliable data about topics, often very personal, related to their violent behaviour on spouses, their own experiences of maltreatment and gender inequality during childhood.

Informed consent was taken from all the respondents before data collection. All respondents were well-explained about the purpose of collecting data from them on particular topics, while confidentiality was guaranteed. Privacy was maintained by the investigators during the interview, by conducting interviews in open spaces in rural areas and closed rooms in urban areas where only interviewer and interviewees were present and utmost care was taken by them to ensure that the interviews are taken in isolation and the respondents would not feel any shame or guilt while responding to the questions especially the sensitive ones.

\section{Results}

\section{IPV and Childhood Gender Inequity Experiences of Men}

This study vividly demonstrated the connotations between the violent behaviour of men against women and the influence of gender inequity family environment in which they grew up. Men's childhood gender inequity experiences are found to be a strong predictor of IPV as odds of IPV among men with high- level childhood gender inequity experiences were 4.31 times those of low- level experiences. Overall, the findings underlined the existence of strong and deeply rooted patriarchal as well as male-dominated gender attitudes internalised within men in the study sites as proximate factors of IPV.

The influential role of violence experiences, especially the early childhood ones, on violence endorsing adult attitude and behaviour has been observed, since long, by many scholars (Heise et al., 1994 \& Gil-González et al., 2007). Recent studies by Thomas (2017) and Thomas (2018a) in support of this finding state that a high prevalence of IPV was found among those men with high- level gender inequity experiences. So, it is apparent that the inequity experiences concerning various aspects of gender in the early years play a pivotal role in moulding adult behaviour as the results proved that men's learned gender equality attitudes, intricately fastened and enlaced with from childhood, correlates with their propensity towards IPV.

Barker et al. (2011) as well reported a clear link between high- level childhood gender inequality experiences of men and their high- level perpetration of IPV. Similarly, attitude towards gender roles, that is, culturally oriented notions regarding what a man and woman should or should not do, is one of the definite predictors 
of IPV identified by many authors (Berkel, Vandiver, \& Bahner, 2004; Thomas, Trivedi, Subhash \& Pathak, 2018).

Many studies have documented how more privileges enjoyed by boys than girls, in traditional families, for example ready meals on table, ironed clothes on hand, more pocket money, more freedom, often inculcate a feeling of superiority within them over women, which in turn ultimately drive adult IPV perpetration by them (Thomas \& Mishra, 2012, p.424). In the present study also definite association in this regard is established as men admitted to being more violent on wives were those with more exposure to childhood violence.

Results of regression co-efficient undoubtedly proved that among childhood gender inequity experiences of men, educational and developmental opportunity domain was the most important factor, followed by other domains namely value, social taboos, gender role, health and nutrition, and social freedom, to explain IPV perpetration by them as the regression equation obtained was IPV $=59.149+$ $.463(\mathrm{EDO})+.350(\mathrm{~V})+.306(\mathrm{ST})+.096(\mathrm{GR})+.073$ $(\mathrm{H} \& N)+.060(\mathrm{SF})$.

\section{IPV and Childhood Violence Experiences of Men}

Theory of cycle of violence conceptualises violence by men on intimate partners as an internalised strategy boys adapt to wield control on spouses, when becoming adults, as a repercussion of witnessing parental violence, especially watching father being cruel on mother, during childhood. Yielded finding of this study approved this argument by establishing strong correlations of IPV with childhood traumatic experiences including parental violence and substantiated the empirical evidence supporting the same from six countries (Heilman, Hebert, \& Paul-Gera, 2014).

Research in domestic violence demonstrated support to this argument that men in their past undergone childhood victimisation as well as exposure to domestic violence, for example, the mother being beaten up by father, are more inclined to become batterers themselves. Gil-
González, et al. (2007. P.21) attributes the aetiology of IPV to an asymmetrically gendered society, which endorses and glorifies undue privileges to men. As suggested by Aziz et al. (2018) and Fulu et al. (2017), boys socialised in societies organised by gender inequality practices and notions are more at risk of using violent ways to exert control on women so as to protect their dominant positions in families and society.

Heilman et al. (2014, p.8) unequivocally presents evidence endorsing significant associations between childhood violence experiences, including witnessing and victimisation, and their propensity to adopt violence as a stress resolving tactic and links witnessing violence upon mothers by partners to the IPV behaviour of their children.

Inequitable gender attitudes, often developed by men as a result of violent atmosphere in which they are grown up (Contreras et al., 2012, p.20), may result into inflicting more violence on spouses as violence is a means they resort to making them adhere to their learned rigid masculine gender roles. At the same time in a study by Priya et al., (2014) perpetrators' violence validating as well as rigidly masculine attitudes have been strongly associated with their childhood exposure to parental violence.

Coker et al. (2002, p.265) explicitly proved the strong influence of various childhood experiences, including violence, on IPV perpetration by adults (odds at 2.5 times). This IPV theory of family violence is underpinned by the finding of the current study which affirms that men who committed more violence on intimate partners were men with a history of severe childhood violence experiences as victims or witnesses.

Correlation results indicated the strong propensity of respondents with violence experiences to inflict IPV upon their spouses in adulthood. International Men and Gender Equity Survey data by Barker et al. (2011) also demonstrated that men who were brought up in families where patriarchal ideology apparently play prominent role to acquiesce women to male dominance showed their more likely to lean to 
aggression for settling a dispute, both within and outside of their intimate partnerships (Contreras et al., (2012).

Results of regression co-efficient undoubtedly proved that among different forms of violence experienced, childhood sexual abuse experience of men was the most important factor, followed by emotional abuse and physical abuse, to explain perpetration of IPV by them in adulthood as the regression equation obtained was IPV = $6.355+.370$ (SA) +.307 (EA) +.115 (PA). It can be inferred that those who had experience of sexual abuse during childhood would be more at risk of perpetration of IPV than those with emotional and physical abuse experiences.

\section{Prevalence of Intimate Partner Violence and Its Proximate Factors}

The pervasiveness of IPV in Gujarat is evident as data analysis found around one-fourth of men reported high-level perpetration and more than half admitted having moderate level perpetration of IPV on their wives. At the same time prevalence of IPV was evident across the study sites, albeit, with varied proportions.

Findings unequivocally suggest a definite trend concerning reported forms of perpetrated violence by men against wives as a substantial proportion of the respondents admitted being physically violent followed by emotionally, economically and sexually violent against their partners.

Similarly, significant variations in the reported prevalence estimates across all forms of IPV were documented by Kalokhe et al. (2016) in India where the highest reported form of abuse was physical in nature though psychological and sexual abuses were also found to be prevalent. Ellsberg, Pena, Herrera, Liljestrand, and Winkvist (2000) too found evidence of physical brutality upon majority women often in conjunction with psychological and sexual violence by intimate partners.

However, a study from Iran revealed a different pattern, wherein majority women (82.6\%) reported being subjected to emotional violence while physical violence was experienced by (43.7\%) (Vakili, Nadrian, Fathipoor, Boniadi, \&
Morowatisharifabad, 2010). Simultaneously, sexual violence was the least reported form of violence $(30.9 \%)$, a finding corroborates with many previous studies.

Chi-square analysis shows significant associations of IPV with educational qualification, income, type of family, area of living and occupation of the perpetrators. All these associations, except occupation, are been confirmed with regression analysis too. Results of logistic regression proved that odds of IPV among men with secondary and college-level education were 0.22 and 0.127 times those of primary level men. This explicitly proved the sheer correlation between IPV and educational attainment of men that how higher-level education acts as a shielding factor against IPV.

This violent behaviour by less-educated married men was consistently highlighted by many researchers including Ackerson, Kawachi, Barbeau, and Subramanian, (2008). Some researchers, nevertheless, found that more educational attainment of women than husbands made them more prone to the victimisation of IPV (Cools \& Kotsadam, 2017).

Similar associations are evident between IPV and monthly income of men as the odds of IPV reported by men with income $20,000 \leq$ is only 0.364 times those of less than $\geq 10,000$. In a previous study Weiner et al. (cited in UNODC, 2018) also investigated the role of income as a driving factor behind men's aggressiveness on women and asserted that batterers were mainly men from very poor and very fewer income categories. At the same time having current experiences of food insecurity by perpetrators which reflect their lower socio-economic status is been reported as an antecedent of IPV by Fulu et al. (2013, p.77).

Present study findings suggest that unemployment is an important individual proximate factor of IPV perpetration by men against spouses and underpinned the shreds of evidence, documented by many past researchers including (Vakili et al., 2010) among them, supporting strong correlations between unemployment and IPV. Similarly, the findings of this study which highlight strong links between 
the type of occupation and propensity towards IPV resonates with the arguments of Priya et al. (2012) that manual labours are more prone to commit IPV than professionals.

Compared with men from urban areas, men from rural areas had higher odds (1.4 times more) of reporting high-level of IPV. From Iran too, a similar pattern is reported, that men belonged to towns and cities committed lowlevel IPV than from rural background (Vakili et al., 2010). Burazeri, Roshi, and Tavanxhi (2006) also reported highly significant correlations between IPV perpetration by men and their backwardness in the level of education, employment, and area of living.

Respondents living in nuclear families, in the present study, reported high- level violence in comparison to those living in joint families. This highlights the protective role played by joint families against partner violence. In contrast to this, Priya et al. (2012) found that in Vietnam men from joint families showed elevated propensity to perpetrate violence than men in nuclear families, while the same study in Nepal could not find any such association.

Young age is been often acknowledged as one of the prominent risk factors of IPV by numerous studies including one from China ( $\mathrm{Tu} \&$ Lou, 2016), yet data analysis in present study could not establish any strong relationship of IPV with age of perpetrators, a contradiction with findings of prior IPV studies conducted in Nepal and Vietnam (WHO, 2010 \& Priya et al., 2012) and a study performed in Sanandaj (Ghazizadeh, 2005), all assert that age is a strong and significant predictor of IPV.

\section{Conclusion}

The findings vividly highlighted the high prevalence of perpetration of IPV, albeit substantial variation across forms of IPV in the reported prevalence estimates, in all sites. It encapsulated better education, high income and secured employment status as protective factors while belonging to nuclear families and rural habitats as predictive factors of IPV. Also, consistent with numerous research findings, this study affirmed the consistent influence of deeply entrenched patriarchal culture, in which often boys are grown up, which sanctions inequitable and rigid gender norms, on their adult behaviour.

Like Decker, Miller, Illangasekare \& Silverman (2013) proclaim, "these norms, which are expressed by individuals and informed by, maintained, and codified at the social or structural level, effectively create a culture in which male perpetration of gender-based violence is tolerated at best and expected at worst" (p.1).

So, policy implications include urgent need to teach lessons of gender parity to children from tender ages. Parents and schools should be oriented in a way that children respect the dignity of all gender and develop attitudes which do not ratify violence upon women and gender inequality. More men and boys, especially those who carry gender-equitable attitudes and well recognized the role of masculinity and gender rigidity in IPV, should be involved in interventions for a total transformation of social notions that implant and reinforce edifice of masculinity that are imperative to create excellent as well as respectful relationships between men and women, and to eradicate perpetration of violence against women completely.

\section{References}

Ackerson, L. K., Kawachi, I., Barbeau, E. M., \& Subramanian, S. V. (2008). Effects of individual and proximate educational context on intimate partner violence: A population-based study of women in India. American Journal of Public Health, 98, 507-14.

Alhabib, S., Nur, U. \& Jones, R. (2010). Domestic violence against women: Systematic preview of prevalence studies. Journal of Family Violence, 25, 369-382. doi:10.1007/s10896-009-9298-4

Atkinson, M. P., Greenstein, T. N., \& Lang, M. M. (2005). For women, breadwinning can be dangerous: Gendered resource theory and wife abuse. Journal of Marriage and Family, 67(5), 1137-1148. 
Aziz, N.N.A., Idris, S.A.M., Ishak, M., Wahid, N. A., \& Yazid, Z.N.A. (2018). Understanding the antecedents of domestic violence against women: A preliminary study. Proceeding -4 th Putrajaya International Conference on Children, Women, Elderly and People with Disabilities (Piccwed 4), 24-25.

Barker, G., Contreras, J. M., Heilman, B., Singh, A K., Verma, R.K., \& Nascimento, M. (2011). Evolving Men: Initial Results from the International Men and Gender Equality Survey (IMAGES). Washington, D.C.: International Center for Research on Women (ICRW) and Rio de Janeiro: Instituto Promundo.

Berkel, L.A., Vandiver, B.J., \& Bahner, A.D. (2004). Gender role attitudes, religion, and spirituality as predictors of domestic violence attitudes in white college students. Journal of College Student Development, 45(2), 119-133.

Burazeri, G., Roshi, E., \& Tavanxhi, N. (2006). Intimate partner violence in the Balkans: the example of Albania. Journal of Public Health, 14, 233. doi:10.1007/s10389-006-0046-4

Contreras, M., Heilman, B., Barker, G., Singh,A., Verma, R., \& Bloomfield, J. (2012). Bridges to adulthood: Understanding the lifelong influence of men's childhood experiences of violence analyzing data from the International Men and Gender Equality Survey. Washington, DC: International Center for Research on women (ICRW) and Rio de Janeiro: Instituto Promundo.

Coker, A. L., Davis, K. E., Arias, I., Desai, S., Sanderson, M., Brandt, H. M., Paige H. Smith, P. H. (2002). Physical and mental health effects of intimate partner violence for men and women. American Journal of Preventive Medicine, 24(4), 260-268.

Cools, S., \& Kotsadam, A. (2017). Resources and intimate partner violence in Sub-Saharan Africa. World Development, 95, 211-230.

Decker, M.R., Miller, E., Illangasekare, S., \& Silverman, J.G. (2013). Understanding gender based violence perpetration to create a safer future for women and girls. The Lancet Global Health, 1(4), e170-e171. doi: 10.1016/S2214109X(13)70085-8
Department of Justice, Canada. (2016). What is family violence? Retrieved on 21 December 2016 from, http://www.justice.gc.ca/eng/cjjp/fv-vf/about-apropos.html

Dunkle, K. L., \& Jewkes, R. (2017). Effective HIV prevention requires gender-transformative work with men. Sexually Transmitted Infections, 83(3), 173-174.

Ellsberg, M., Pena, R., Herrera, A., Liljestrand, J., \& Winkwist, A. (2000). Candies in hell: Women's experiences of violence in Nicaragua. Social Science and Medicine, 51, 1595-1610. doi: 10.1016/S0277-9536(00)00056-3

Fulu, E., Warner, X., Miedema, S., Jewkes, R., Roselli, T., \& Lang, J. (2013). Why do some men use violence against women and how can we prevent it? Quantitative findings from the United Nations multi-country study on men and violence in Asia and the Pacific. Bangkok, UNDP, UNFPA, UN Women and UNV.

Fulu, E., Miedema, S., Roselli, T., McCook, S., Chan, K, L., Haardörfer, R., \& Jewkes, R.. (2017). Pathways between childhood trauma, intimate partner violence, and harsh parenting: findings from the UN Multi-country Study on Men and Violence in Asia and the Pacific on behalf of the UN Multi-country Study on Men and Violence study team p. 13. Retrieved on 13 April 2017 from,

file:///C:/Users/Compaq/Downloads/PIIS22141 09X17301031.pdf

Ghazizadeh, A. (2005). Domestic violence: A cross-sectional study in an Iranian city. Eastern Mediterranean Health Journal, 11, 880-887.

Gil-González, D., Vives-Cases, C., Ruiz, M. T., Carrasco-Portiño, M., \& Carlos Álvarez-Dardet, C. (2007). Childhood experiences of violence in perpetrators as a risk factor of intimate partner violence: a systematic review, Journal of Public Health, 30(1)14-22. doi:

10.1093/pubmed/fdm071

Glinski, A., Schwenke, C., O'Brien-Milne, L., \& Farley, K. (2018). Gender equity and male engagement: It only works when everyone plays. Washington, D.C, ICRW. 
Gracia, E., \& Merlo, J. (2016). Intimate partner violence against women and the Nordic paradox. Social Science \& Medicine, 157, 27-30.

Gupta, A. (2014). Reporting and incidence of violence against women in India, Working paper. Retrieved on 27 March 2019 from, http://riceinstitute.org/wordpress/wpcontent/uploads/downloads/2014/10/Reportin g-and-incidence-of-violence-against-women-inIndia-working-paper-final.pdf.

Heilman, B., Hebert, L., \& Paul-Gera, N. (2014). The making of sexual violence: How does a boy grow up to commit rape? Evidence from five IMAGES countries. Washington, DC: International Center for Research on Women (ICRW) and Washington, DC: Promundo.

Heise, L., Pitanguy, A., \& Germaine, A. (1994). Violence Against Women: The Hidden Health Burden. Washington D.C. The World Bank.

Hendra, J., FitzGerald, I., \& Seymour, D. (2013). Towards a new transformative development agenda: The role of men and boys in achieving gender equality. Journal of International Affairs, 67(1), 105-122.

Johari, S. (2017). Six Facts of the Statistical Analysis of Domestic Violence Cases in 2015.

Jewkes, R.K. (2002). Intimate partner violence: causes and prevention, The Lancet, 359, 14231429.

Kalokhe, A., Rio del, C., Dunkle, K., Stephenson, R., Metheny, N., Paranjape, A., Sahay, S. (2016). Domestic violence against women in India: $A$ systematic review of decade of quantitative studies. Global Public Health 12(4), 498-513. doi: 10.1080/17441692.2015.1119293

Margolin, G., B. Burman, R.S. John, and M. O'Brien (1990). The Domestic Conflict Instrument, Los Angeles: University of Southern California.

Marilyn, F. (2010). Hunger for healing: is there a role for introducing restorative justice principles in domestic violence services. In Fernandez, Marilyn, Restorative Justice for Domestic Violence Victims an Integrated Approach to their Hunger for Healing, Lanham, Maryland: Lexington Books, p. 5, ISBN 9780739148068
Pines, E.W. (2017). Intimate partner violence among women and trauma informed care: An international perspective. Madridge Journal of Womens Health Emancipation, 1(1), 11-15. doi: 10.18689/mjwh-1000104

Priya, N., Abhishek, G., Ravi, V., Khuat Thu, H., Mahesh, P., Tran Giang, L., ......... Prabhat, L. (2012). Study on gender, masculinity and son preference in Nepal and Vietnam. New Delhi, International Center for Research on Women.

Priya, N., Abhishek, G., Ravi, V., Aarushi, K., Nizamuddin, K., Dhanashri, B., ... Sanjay, K. (2014). Study on masculinity, intimate partner violence and son preference in India. New Delhi, International Center for Research on Women.

Priyali, S. (2015). I was like his sex slave and not his wife': An Indian woman tries to criminalize marital rape. Retrieved on 24 June 2017 from, http://www.womensmediacenter.com/womenunder-siege/i-was-his-sex-slave-and-not-wifeindian-woman-criminalize-marital-rape.

Saenger, A.S. (2000). Family Violence: A review of the dysfunctional behaviour patterns, Retrieved on 13 July 2015 from, http://www.mincava.umn.edu/documents/fami lyviolence/familyviolence html\#rudo 1996

Sarkar, M. (2010). A study on domestic violence against adult and adolescent females in a rural area of West Bengal. Indian Journal of Community Medicine, 35(2), 311-315. doi: 10.4103/0970-0218.66881

Sharma, I. (2015). Violence against women: Where are the solutions? Indian Journal of Psychiatry, 57(2), 131-139. doi: 10.4103/00195545.158133

Smith, E. (2008). African American men and intimate partner violence. Journal of African American Studies, 12, 156-179. doi: 10.1007/s12111-008-9039-4

Straus, M.A. (1979). Measuring Intra family Conflict and Violence: The Conflict Tactics Scales. Journal of Marriage and the Family 41, 75-88.

Thomas, B., \& Mishra, S. (2012). Fertility Behaviour of Women: Is son preference still a 
proximate factor? International Journal of Social and Economic Research, 2(2), 419-426.

Thomas, B. (2017). Intimate partner violence: Exploring links with men's childhood gender inequality and violence experiences.

Proceedings of the 3rd World Conference on Women's Studies, 1-11. doi:

10.17501/wcws.2017.2101

Thomas, B. (2018a). Intimate partner violence as reported by men in India: Exploring pathways with childhood gender inequity and violence experiences of perpetrators. Man in India. 98(34), 605-616.

Thomas, B. (2018b). Violence Scale.H.P. Bhargava Book House, Agra. ISBN: 978-93866616-54-8

Thomas, B. (2018c). Gender Equality Scale. H.P. Bhargava Book House, Agra. ISBN: 93-86616-53$\mathrm{X}$

Thomas, B., Trivedi, H. P., Subhash, R., \& Pathak, S. (2018). Who perpetrates violence on own spouses? Evidence from India. Proceedings of the 4th World Conference on Women's Studies, 3 (1), 16-24. doi: 10.17501/wcws.2018.3102

Tu, X., \& Lou, C. (2017). Risk factors associated with current intimate partner violence at individual and relationship levels: a crosssectional study among married rural migrant women in Shanghai, China, BMJ Open, 012264, 1-9. doi: 10.1136/bmjopen-2016-012264

United Nations. (2017). Message on International Day for the elimination of violence against women, Retrieved on 25 November 2017from,http://www.unis.unvienna.org/unis/ en/pressrels/2017/unissgsm846.html

United Nations. (2018). Violence against women a 'mark of shame' on our societies. Retrieved on 30 September 2019 from, https://www.vaticannews.va/en/world/news/2 018-11/united-nations-day-violence-womenguterres-phumzile.html

UNODC (2018). Global Study on Homicide 2018, (Vienna, 2018)
Vakili, M., Nadrian, H., Fathipoor, M., Boniadi, F.,\& Morowatisharifabad M. (2010). Prevalence and determinants of intimate partner violence against women in Kazeroon, Islamic Republic of Iran. Violence and Victims, 25(1), 116-127.doi: 10.1891/0886-6708.25.1.116

World Health Organization/London School of Hygiene and Tropical Medicine. (2010).

Preventing intimate partner and sexual violence against women: Taking action and generating evidence. Geneva: World Health Organization, 5-33.

World Health Organization. (2015). Intimate Partner Violence and Alcohol Fact Sheet, World Health Organization.

World Health Organization. (2017). Violence against women- Key Facts. Retrieved on 15 August 2019 from, http://www.who.int/newsroom/factsheets/detail/violence-againstwomen.

Yakubovich, A. R., Stöckl, H., Murray, J., Melendez-Torres, G, J., Steinert, J. I., Glavin, C.E.Y., \& Humphreys, D. K. (2018). Risk and Protective Factors for Intimate Partner Violence Against Women: Systematic Review and Metaanalyses of Prospective-Longitudinal Studies, American Journal of Public Health, 108(7), 1-11. doi: 10.2105/AJPH.2018.304428

\section{Acknowledgement}

This article is the outcome of a major project titled "Intimate Partner Violence: Exploring Links with Men's Attitude towards Gender Equality and Childhood gender Inequality \& Violence experiences" undertaken by us during 20162018 and we acknowledge the financial as well as technical support provided by Indian Council of Social Science Research (ICSSR), New Delhi towards successful completion of this project.

\section{About the Authors}

Dr. Bigi Thomas is currently working as Reader in the Department of Social Work, Sardar Patel University, Gujarat, India. After having Bachelor of Commerce (BCom) from Mahatma Gandhi University, Kerala, in 1992, she completed Master of Social Work (MSW) from Nagpur University, Maharashtra with Gold Medal and 
PhD in Social Work from Shivaji University, Maharashtra in 2008. She had cleared National Eligibility Test and received the junior research fellowship of University Grants Commission, New Delhi. Her interest areas are Gender, Health and Migration.

Prof. (Dr.) H.P. Trivedi is currently working as a Professor in the Department of Economics of Sardar Patel University, Gujarat, India. He did his graduation in Economics in 1980 from M. S. University, Gujarat and Master degree with first rank in 1982. He had completed his PhD in Economics in 1990 from Sardar Patel University, Gujarat. He had worked in various capacities including Dean, Faculty of Arts, Head, Department of Economics, Director, Centre for Agro Economics to name the few. His areas of interest include agro economics, gender budgeting and human development.

Prof. (Dr.) Rema Subhash- is a Professor in the Department of Home Science of Sardar Patel
University, Gujarat, India. After completing graduation as well as post-graduation from Madras University, she obtained PhD in Home Science from Sardar Patel University, Gujarat. A number of projects sponsored by UGC, DBT, ICMR and ICSSR are been completed by her. Her interest areas are nutrition\& malnutrition, Osteoporosis and women issues.

Dr. Sangitha Pathak is an Associate Professor, Psychology Department of Sardar Patel University, Gujarat, India. She had completed her graduation and post-graduation in psychology as well as Social Work from M.S.University, Gujarat. She gained her PhD in psychology from South Gujarat University in 1998. She has completed many projects sponsored by UGC and is an active member of many academic bodies. Her interest areas are applied psychology, social psychology and counselling. 